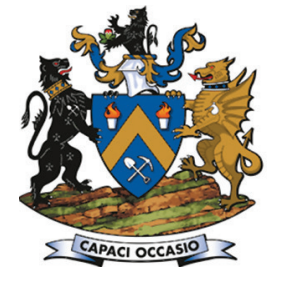

Affiliation:

1 Department of Engineering and Technology Management, University of Pretoria, Pretoria, South Africa.

${ }^{2}$ Mintek, Randburg, South Africa.

Correspondence to:

M. van Rooyen

Email:

Vanrooyen.michelle.up@gmail. com

\section{Dates:}

Received: 7 Aug. 2019

Revised: 7 Feb. 2020

Accepted: 28 Feb. 2020

Published: April 2020

\section{How to cite:}

van Rooyen, M., van der Lingen,

E., and Ross. V.

Technology commercialization

front-end framework: Metallurgical

industry.

The Southern African Insitute of

Mining and Metallurgy

DOI ID:

http://dx.doi.org/10.17159/2411$9717 / 867 / 2020$

\title{
Technology commercialization front-end framework: Metallurgical industry
}

\author{
M. van Rooven ${ }^{1,2}$, E. van der Lingen', and V.E. Ross ${ }^{2}$
}

\begin{abstract}
Synopsis
The development and commercialization of technologies within the metallurgical industry often spans a time-frame of decades. This paper proposes a managerial framework that aims at increasing the success rate and speed of technology commercialization within this industry, focusing on the front end of the process.

A case study research strategy was applied, with an in-depth evaluation of two cases. The cases involved technologies that were developed by a metallurgical research and development organization. For each of the cases, secondary data was collected, followed by interviews. The data was evaluated, compared, and consolidated into a framework. For the technology development stages of concept development, and for research and development, important factors were identified that contribute to the successful development of technologies with the objective of commercialization. During concept development, the most important factor was determined to be the identification of the need or opportunity within the market, whereas the most important factors during research and development were determined to be the involvement of a project champion, a suitable team, and a potential implementer. The central driver of technology commercialization was identified to be the market, along with the fulfilment of a need or opportunity within the market.
\end{abstract}

\section{Keywords}

Framework, technology development, technology commercialization, technology innovation, metallurgical industry.

\section{Introduction}

Technological development leads to economic growth (Schumpeter, 1939). This statement, made 80 years ago, still holds true today. However, technological development can contribute to economic growth only if technologies are commercialized. The progression from ideation to commercialization seems quite straightforward; however, it is typically a difficult and slow process (Cetindamar, Phaal, and Probert, 2010). Technology commercialization seems to be a challenge in any industry; and the metallurgical field is no different, with time-frames for technology innovation typically spanning more than a decade. This creates a considerable challenge for researchers during the development of technologies in the metallurgical industry, since the market might change as the technology is being developed, potentially resulting in the need for changes to the technology during its development.

While several frameworks for successful technology commercialization have been developed, none of these places a focus on the metallurgical industry specifically. Therefore, it is believed that a framework that highlights the important factors that contribute to successful technology commercialization would assist technology managers within this industry.

Technology development is typically performed in stages. These may be in the form of stage-gates (Cooper, 1990; Cooper, 2014), life-cycles (Cetindamar, Phaal, and Probert, 2010; Taylor and Taylor, 2012; Geissdoerfer, Savaget, and Evans, 2017), or technology readiness levels (Sauser and Verma, et al., 2006). Figure 1 illustrates the impact to risk, uncertainty, and cost over the time-frame of a project such as the development of technology. As technology development progresses, risk and uncertainty decrease, whereas the cost of changes increases dramatically. The importance of a structured, focused technology development process, along with proper management of this process during the early stages of the project time-frame, is therefore emphasised.

The objective of this research was to identify the key factors that influence the successful commercialization of technologies, focusing on the early stages of the technology innovation process, and to consolidate these factors into a framework for a successful technology commercialization frontend for the metallurgical industry. 


\section{Technology commercialization front-end framework: Metallurgical industry}

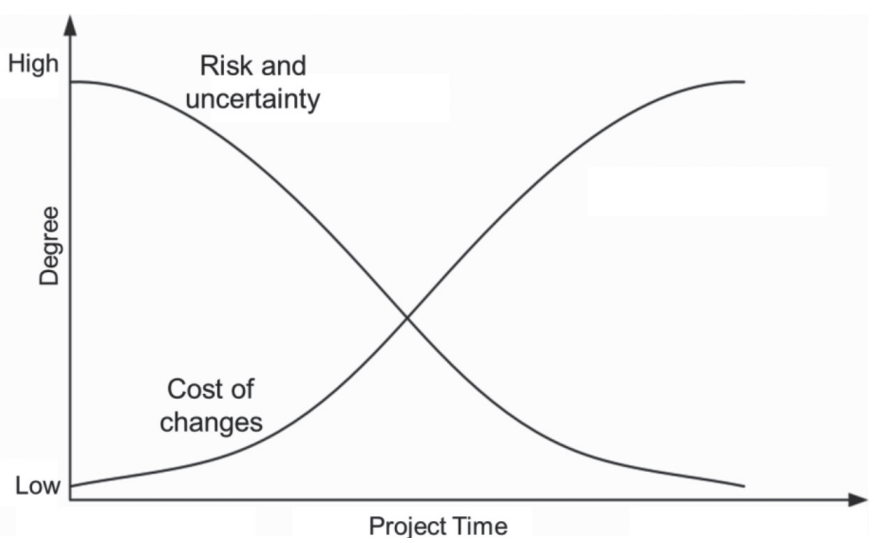

Figure 1-Impact of changes to variables over the project time-frame (Sherman, 2015)

\section{Literature}

Over the years, competition has become more focused on knowledge, and this is especially true of technology-intensive industries (Lichtenthaler, 2006). Along with the growing importance of knowledge, transactions of technologies between organizations and their external environment have also increased considerably. This results in the need for organizations to manage both the technological knowledge inside the firms and the transfer of technologies and products to the external environment. Many firms experience difficulties in the management of these activities (Lichtenthaler, 2006).

Lichtenthaler, a frequent publisher on aspects of external technology commercialization and open innovation, aptly states that it is considerably more difficult to commercialize technologies than it is to commercialzse products (Lichtenthaler, 2008a). Lichtenthaler (2006) explains that, to gain maximum economic benefit from the commercialization of technologies, an organization should develop a strategy for technology commercialization, and not merely perform ad hoc operations in the hope of achieving success.

The metallurgical industry is described by Bakalarczyk (2013) as the most important branch of the processing industry, with a focus on the preparation of extracted ores to obtain pure metals or their derivatives. Advances in the metallurgical industry rely heavily on technological development and on the successful commercialization and implementation of these technologies.

Innovation has evolved considerably over the past number of years. Of particular interest in the work by Tidd (2006) is the discussion of the five generations of innovation models, from a linear model of market pull and technology push in the first and second generations, to extensive networking, integration, and a systems approach in the fifth generation. Support in favour of integrated, nonlinear innovation models is provided by Alekseevna (2014), who highlights that such models enable the involvement of the customer and enhance decision-making during the innovation process. The nonlinearity of the technology innovation process is promoted further by Ross and Kleingeld (2006), with the innovation process represented as a continuous, interlinked, and integrated sequence of four main stages - invent, ideate, introduce, and implement.

Van der Heiden et al., (2016) developed a framework that shows the multifaceted nature of technology commercialization and the strategic considerations that are required during the innovation process. Their framework highlights which technology commercialization aspects are important - such as technical specifications, user characteristics and requirements, appropriate technology selection, and the policy environment. An integrated framework by Blank (2013) provides additional insights related to technology commercialization; in particular, this model emphasises the importance of customer involvement and focused development efforts with the sole aim of satisfying the customer requirements.

The cyclical nature of open innovation and product development is well illustrated by Berkhout et al., (2006). This framework is insightful and informative; each link illustrated in the model is contextualized and rationalized, and the synergies between all aspects are explained to promote understanding. The cyclical, integrated nature of the model enables regular feedback to all processes within the model. Van der Duin, Ortt, and Kok (2007) applied this model in an actual innovation process, and emphasised that feedback allows participants to be reminded of the consequences of their actions, and enables fast responses if adjustments to the process are necessary. Ford et al. (2014) also applied this model in an operational environment, and indicated that the application of innovation may start anywhere in the model, and that prior innovations may inspire new ideas due to the interactive and integrated nature of the model. Berkhout et al. (2006) also emphasised the importance of open innovation, as supported by Lichtenthaler (2008b), Cetindamar, Phaal, and Probert (2010), and Kirchberger and Pohl (2016), and of early engagement between the researchers and the market, as supported by Markman, Siegel, and Wright (2008) and Polampally (2013). In a subsequent article, Berkhout, Hartmann, and Trott (2010) highlight the value of this model, and state that it links the scientific aspects of research and development (R\&D) to the market aspects where commercialization occurs.

None of the frameworks identified in the literature were specifically developed to aid successful technology commercialization within the metallurgical industry. The applicability of the frameworks to the metallurgical industry is therefore unknown. It was based on these shortcomings that the need for a new framework for a successful technology commercialization front-end for the metallurgical industry was identified.

\section{Conceptual framework}

The conceptual framework, illustrated in Figure 2, was developed from insights from key literature sources, such as Berkhout et al. (2006), Ross and Kleingeld. (2006), Tidd (2006), and van

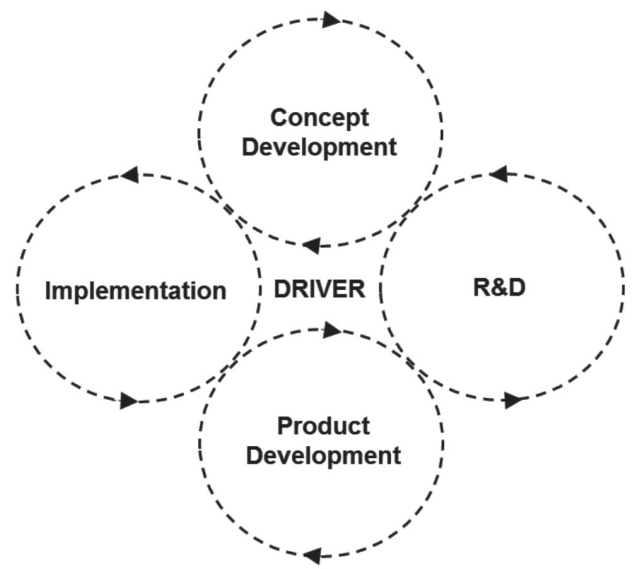

Figure 2-Conceptual framework 


\section{Technology commercialization front-end framework: Metallurgical industry}

der Heiden et al. (2016). The conceptual framework illustrates the four technology innovation stages - concept development, $R \& D$, product development, and implementation - which are integrated cyclically, highlighting the fluid and nonlinear nature of technology innovation.

Each stage has distinct characteristics and a particular purpose within the overall technology innovation process. Concept development involves formulating the vision or the purpose of the technological concept; several ideas are developed, from which the most likely ideas are selected for further evaluation (Geissdoerfer, Savaget, and Evans, 2017). During this stage, innovation is initiated by using the identification of a problem that is translated into a consequent need, and the creation of ideas to satisfy the particular need (Ross and Kleingeld., 2006). Specific researcher traits are necessary for successful technology commercialization, such as businessminded thinking, creativity, and motivation (Ismail, Nor, and Sidek, 2015; Kirchberger and Pohl 2016). Focus is also placed on market analysis (Polampally, 2013), networking (Lichtenthaler, 2006), and the development of a conceptual business case for the technology (Geissdoerfer, Savaget, and Evans, 2017).

Various internal and external interactions occur during concept development (Ungureanu, Pop, and Ungureanu, 2016). Internal interactions include developing various new concepts and revising new ideas, as well as evaluating and selecting concepts for further evaluation (Geissdoerfer, Savaget, and Evans, 2017). The external interactions involve concepts such as the formation of networks and open innovation (Lichtenthaler, 2008b; Cetindamar, Phaal, and Probert, 2009; Aarikka-Stenroos, Sandberg, and Lehtimäki, 2014; Ostendorf, Mouzas, and Chakrabarti, 2014; Kirchberger and Pohl, 2016; Ungureanu, Pop, and Ungureanu, 2016).

$R \& D$ involves experimentation and technological development (Geissdoerfer, Savaget, and Evans 2017). Ross and Kleingeld (2006, p. 73) explain that this stage involves the verification of scientific principles and the execution of research to develop a 'formally documented basis of understanding'. The application of stage-gates (Cooper, 1990, 2014), technological life-cycles (Cetindamar, Phaal, and Probert, 2010; Taylor and Taylor, 2012; Geissdoerfer, Savaget, and Evans, 2017) and technology readiness levels (Sauser et al., 2006) is likely to form the dominant function during $R \& D$ in order to undertake a structured approach to the experimentation process. Specification of the technical characteristics and user requirements (van der Heiden et al., 2016) are also key aspects that require attention during $\mathrm{R} \& \mathrm{D}$.

Numerous internal and external interactions (Ungureanu, Pop, and Ungureanu, 2016) occur during $R \& D$. Internal technological development is likely to be performed, with further tests based on outcomes from previous work, which might also indicate that the technology is not viable, resulting in the need for a decision to abandon further development. Moreover, the internal interactions comprise collaborative research that is conducted within an organization, involving various researchers, technical specialists, and different departments. The external interactions during $\mathrm{R} \& \mathrm{D}$ might involve partnerships, networks, and open innovation (Lichtenthaler, 2008b; Cetindamar, Phaal, and Probert, 2009; Aarikka-Stenroos, Sandberg, and Lehtimäki, 2014; Ostendorf, Mouzas, and Chakrabart, 2014; Kirchberger and Pohl, 2016; Ungureanu, Pop, and Ungureanu, 2016). The specifications of technology characteristics and user requirements (van der Heiden et al., 2016) are likely to be obtained from a potential user or implementer who will probably be external to the organization.

During any stage of technology innovation, external stimuli might prompt ideas for new technological concepts (Geissdoerfer, Savaget, and Evans, 2017), while licensing of the technology may also occur during any stage (Barr et al., 2009; van der Heiden et al., 2016). These notions are depicted by the perforated borders surrounding the technology innovation stages (Figure 2), highlighting the interactive nature of the process.

The conceptual framework depicts the technology innovation process that revolves around the existence of a driver of technology commercialization. Technology commercialization would not be possible in the absence of a driver, irrespective of the dedication that might have been applied to the development of the technology during the innovation process.

This study aimed to identify the driver of technology commercialization, along with an evaluation of internal and external factors influencing the technology innovation stages of concept development and $R \& D$ (Figure 2). An in-depth evaluation of the stages of product development and implementation was excluded from the scope of this study.

\section{Research methodology}

This study followed a qualitative research design, enabling a deeper understanding of the topic that was studied. A theorybuilding research approach was followed by the introduction of new concepts into existing frameworks. Due to the exploratory nature of the topic, a case study research strategy was selected.

A single organization that focuses on $R \& D$, innovation, and technology commercialization within the metallurgical industry was selected as the unit of analysis for the study. Within the organization, four cases were selected, and from these, two for in-depth evaluation, namely Case 1 and Case 2 as shown in Figure 3 . The failed and successful cases are reported in van Rooyen (2018) and, as similar results were obtained for these cases as for Cases 1 and 2, these are not discussed in depth.

For both cases that are described in this paper, data was collected by secondary data analysis, using internal company reports and publications, and by interviewing a case-specific technical expert on an in-person, one-to-one basis. This was followed by a one-to-many, in-person focus group interview for Case 1. For Case 2, insufficient informants were available to

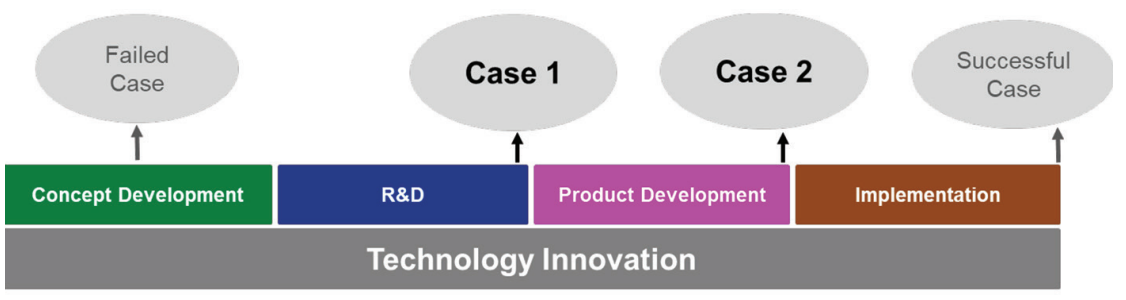

Figure 3-Selection of cases 


\section{Technology commercialization front-end framework: Metallurgical industry}

participate in a one-to-many focus group interview, and so an in-depth interview with a second case-specific technical expert was subsequently conducted. This highlights the implication of the long technology development time-frames that are typically experienced in the metallurgical industry. Most of the team members who were involved in the development of the Case 2 technology resigned or retired from the organization during the technology development period. In total, eight people were interviewed for this study, and each person was purposively selected, based on his/her in-depth knowledge of the selected cases and expertise in technology development and commercialization.

From the publications that were evaluated as part of the literature review, as well as the secondary data analysis that was performed for each case, factors that contribute to successful technology commercialization were identified. The factors were coded for the technology innovation stages of concept development and $R \& D$ to form an initial template that was used as the basis for the collection of data. Figure 4 shows the data acquisition template with the initial factors that were identified as contributors to successful technology commercialization, along with a brief explanation of each factor. All the factors that were listed for the stages of concept development and $R \& D$ were discussed with the respondents to determine what impact the absence or presence of the factor had on the commercialization of the technology. Respondents were also asked for potential unidentified factors to add to those in the template.

As the data collection process progressed, the template was updated with new insights where relevant. During the interviews, the factors were discussed and ranked according to importance. Rankings were done qualitatively, based on the views of the interviewees. During the focus group interview, the respondents discussed each factor with one another, and full agreement on the rank of each factor was obtained. The factors contained in the final template were included in the framework for a successful technology commercialization front-end for the metallurgical industry.

\section{Background of the selected cases}

Both technologies that were selected for case study evaluation were developed by the metallurgical $R \& D$ organization, the unit of analysis for this research study. The cases were selected based on the availability of secondary data and informants to interview.

Case 1 is an acid mine drainage treatment technology, the development of which began around 1990. Numerous laboratory test programmes and pilot plant campaigns were performed between 1990 and the early 2000s; however, the technical viability of the complete flow sheet had not been demonstrated. Around 2009, design changes were made to the process, and further test programmes were conducted on a laboratory and pilot plant scale. The technology is currently nearing completion of the $R \& D$ stage. The organization has performed extensive experimentation over the years, without the involvement of a potential implementer.

Case 2 is a magnesium processing technology. Development of this technology began in the 1980s; however, after several years of development, market interest declined, and so development was halted. Around 1998, market interest was renewed and the development of the technology was revived. A consortium of investors was formed, including an intended implementer, and this facilitated the fast-tracking of technology development. The technology was in the product development stage, nearing Implementation, when the market conditions again became unattractive. Along with changes in the market conditions, the intended implementer made the strategic decision to withdraw all commercial activities from the magnesium market. The technology has thus not yet been commercialized.

\section{Discussion of results}

The initial data acquisition template (Figure 4) was used as the basis for the in-depth, one-to-one, in-person interview with the Case 1 technical expert. The technical expert suggested that two additional factors be included in the data acquisition template for the stage of concept development: (i) a preliminary concept review, and (ii) involvement of the implementer as early as possible. The Case 1 technical expert also suggested that the involvement of the implementer should be added to the $R \& D$ stage of the data acquisition template. An interesting finding was made: during all subsequent interviews that were conducted, no further additional factors were suggested; the only differences in the findings between the various interviews were slight variations between the rankings of the factors. This was a comforting finding, as it proved that relevant factors were collected from the case-specific secondary data; and the subsequent interviews validated these factors.

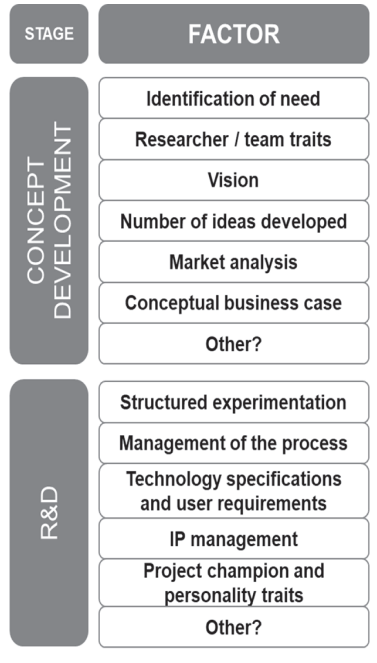

Figure 4-Data acquisition template - initial factors

\begin{tabular}{|l|} 
EXPLANATION \\
The industry/customer need that the technology will satisfy. \\
Specific traits to ensure presence of required skills and knowledge. \\
The vision and purpose of the technology. \\
Different options considered to solve the problem and satisfy need. \\
Awareness and analysis of market, competitors, etc. \\
Business case to determine conceptual feasibility. \\
Any other factors that the interviewees consider important? \\
A structured experimentation approach, with goals, decision-points, etc. \\
Proper management of the development process. \\
Accurate identification of technology specifications and user \\
requirements. \\
The management of intellectual property (IP) during the process. \\
$\begin{array}{l}\text { Person to lead team and development activities, with suitably-skilled } \\
\text { team members. } \\
\text { Any other factors that the interviewees consider important? }\end{array}$
\end{tabular}




\section{Technology commercialization front-end framework: Metallurgical industry}

\begin{tabular}{|c|c|c|c|}
\hline STAGE & RANK & CASE 1 & CASE 2 \\
\hline & 1 & - Identification of need & $\begin{array}{l}\text { - Identification of need } \\
\text { - Market analysis } \\
\text { - Implementer involvement * }\end{array}$ \\
\hline 桌 & 2 & $\begin{array}{l}\text { - Vision } \\
\text { - Market analysis } \\
\text { - Conceptual business case }\end{array}$ & - Conceptual business case \\
\hline 邑 & 3 & - Preliminary concept review * & - Preliminary concept review * \\
\hline\llcorner & 4 & - Researcher/ team traits & - Vision \\
\hline 8 & 5 & - Number of ideas developed & - Researcher / team traits \\
\hline & 6 & - Implementer involvement * & - Number of ideas developed \\
\hline
\end{tabular}

Figure 5-Cases 1 and 2: Concept development ranked factors

\section{Concept development}

During the interviews that were conducted for the evaluation of Cases 1 and 2, numerous similarities were found between the rankings of the factors related to the stage of concept development. Several factors were ranked as equally important, and so obtained an identical ranking. The ranked factors that impact technology commercialization during the stage of concept development that were obtained during the interviews for the evaluation of Cases 1 and 2 are given in Figure 5.

A difference was found between the rankings for the formulation of the vision and purpose of the technology; this factor received a ranking of 2 for Case 1, while a ranking of 4 was assigned for Case 2. When this factor was considered, it was mentioned during the evaluation of both cases that the market analysis and business case reviews were highly important. Furthermore, the second Case 2 technical expert emphasised the challenge of the long time-frames that are typical during the development of metallurgical processes and the changes that are experienced in the market during technology development. Therefore, it makes sense that the vision and purpose of the technology should be defined clearly, and reviewed, during the long time-frame of the technology development. This is to ensure that the vision and purpose of the technology remain relevant, and are updated if required as the market and industry experience changes.

Slight differences were found in the rankings of the factors for the market analysis, researcher/team traits, and the number of ideas that were developed; the rankings of these factors differed by one integer between the two cases. Probably the most interesting finding for the rankings of the factors for the concept development stage relates to the involvement of the implementer: for Case 1, this factor was ranked as least important, whereas, for Case 2, this factor was ranked as one of the most important. The factors were ranked according to importance, based on the qualitative views of the informants, and no definitive, quantitative assessment was made; thus another way to explain the difference in the rankings was needed. When Case 2 technology is considered, the importance of the involvement of the implementer as early as possible during the developmental stages of the technologies is clearly emphasised. When Case 1 technology is considered, this technology is not yet commercialized, and no implementer has been involved during its development. It is with this in mind that it seems reasonable to assign a greater weight to the importance of the ranking for Case 2 when the involvement of the implementer is considered.

When the findings from the two cases for the stage of concept development were considered, some similarities in the views of the informants were found, as well as some differences; this can be seen by the rankings of the various factors between the cases (Figure 5). Since these factors were ranked on a qualitative basis, reflecting the personal views of the informants, no definitive and quantitative analysis can be made regarding exact rankings, nor was this intended. The second Case 2 technical expert was of the view that the three most important factors should receive more focused attention, while the remaining factors might share a similar level of importance, albeit a lower level than the top three. This view might be helpful when the overall rankings of the factors for both cases are combined. When the top three ranked factors are classified as the 'most important factors', and the factors that were assigned lower rankings are classified as the 'remaining factors', the results are as shown in Figure 6.

While some of the factors were ranked differently between the various respondents during the interviews, some were ranked identically as 'most important'. For the stage of concept development, the factor that was ranked as most important for both cases is the identification of the need or opportunity for the envisioned technology. This top-ranked factor is highlighted in bold italic in Figure 6.

During concept development, researchers and technology managers need to ensure that the vision and purpose of the technology are clearly defined, understood, and aligned with

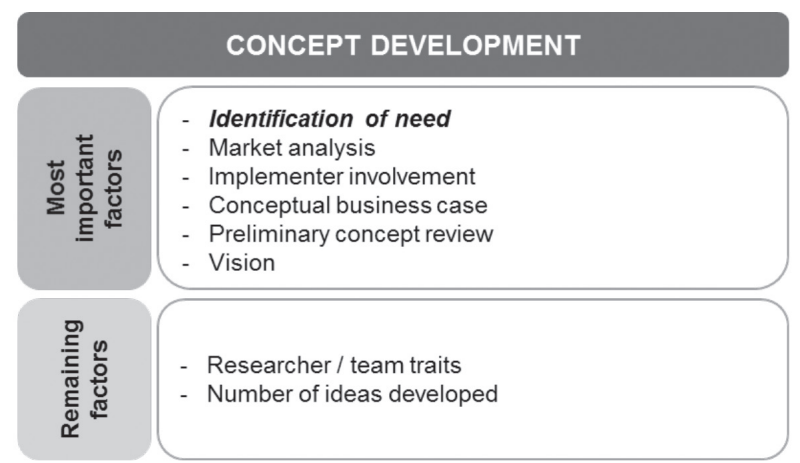

Figure 6-Concept development: Final factors 


\section{Technology commercialization front-end framework: Metallurgical industry}

CASE 1

Figure 7-Cases 1 and 2: ranked key factors in the R\&D stage

all stakeholder expectations. Early involvement of a potential partner or implementer is preferred; however, this might not be possible at such an early stage of technology development. Attention should be paid to the identification of the need or opportunity in the market, and this is likely to be supported by a market analysis. Furthermore, researchers should ensure that a conceptual business case for the technology is developed and that sufficiently detailed technology concept reviews are conducted by suitable technical experts.

\section{$R \& D$}

During the interviews that were conducted for the stage of $R \& D$, various similarities and differences were found between the ranks of the factors for Cases 1 and 2. Several factors were ranked as equally important and received an identical ranking. The ranked factors for Cases 1 and 2 that impact technology commercialization during $R \& D$ are indicated in Figure 7.

Interestingly, for both cases the presence of a project champion (to drive and lead the development activities), along with the personality traits of the project team (ensuring the presence of relevant knowledge and skills), and the involvement of the implementer (to provide the technology specifications and user requirements) were ranked as most important factors for the $R \& D$ stage. A further interesting finding was made: for the project team personality traits, the informants for both cases specifically mentioned the importance of the traits of perseverance and logical thinking during the $R \& D$ stage. This is an important insight because, in practice, organizations generally have limited resources, and seldom have the luxury of being able to assign team members based on their personality traits. However, this study shows that certain personality traits, such as perseverance and logical thinking, are key success factors for technology innovation; and this should be considered during the allocation of team members.

The factor related to the specification of technological characteristics and user requirements received a ranking of 4 for Case 1 and 2 for Case 2. The envisioned implementer typically provides the technical specifications and user requirements; thus, as with the explanation related to the ranking of the involvement of the implementer during the concept development stage, it is also believed to be reasonable that a greater weight be assigned to the ranking for this factor for Case 2 . Further minor differences between the rankings of the various factors were found between Cases 1 and 2. The ranked factors related to $R \& D$ were grouped into the 'most important factors' and 'remaining factors', and the resultant list is shown in Figure 8.
During the evaluation of both cases, certain factors were ranked as 'most important' for the $R \& D$ stage; these factors are the presence of the project champion and relevant personality traits of the team members, and the involvement of the implementer. The top-ranked factors are highlighted in bold italic in Figure 8.

During $R \& D$, the identification of a suitable project champion is important: a person who is capable of motivating and steering the project team, ensuring that a structured technology development approach, with appropriate experimentation, is followed. The technology development should be based on an accurate definition of the specifications of the technology, with properly defined technology standards and user requirements. The identification and involvement of a potential implementer becomes considerably more important during $R \& D$, since an implementer is in the best position to identify the minimum experimentation that is required and to stipulate the technical specifications and user requirements, along with the provision of relevant market information.

\section{Technology commercialization driver}

During the evaluation of Cases 1 and 2, it became clear that the existence of a market, along with the existence of a need or opportunity within that market, is an exceptionally important driver for technology commercialization. Several studies suggest that the driver of technology commercialization is a susceptible market, along with an identified need or opportunity within the market (Markman, Siegel, and Wright, 2008; Polampally, 2013; Kirchberger and Pohl, 2016). The market involves aspects such as policies, regulations, sustainability, environmental aspects,

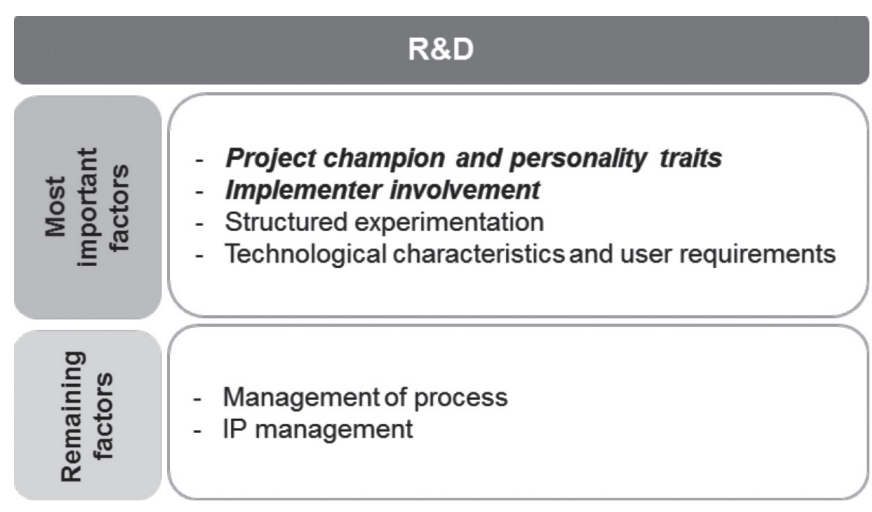

Figure 8-R\&D: Final factors 


\section{Technology commercialization front-end framework: Metallurgical industry}

risk, investment conditions, and access to finance (van der Heiden et al., 2016).

Needs and opportunities have to exist within the market, resulting in a gap that will enable the commercialization of a technology that satisfies the identified need or opportunity (Polampally, 2013). Although most factors that were identified as part of this study were present during the development of Case 2, the poor market condition was the main reason for the unsuccessful commercialization of this technology.

\section{Technology commercialization front-end framework for the metallurgical industry}

The most important factors that influence technology commercialization during concept development (Figure 6) and $R \& D$ (Figure 8) were converted into a graphical framework for a successful technology commercialization front-end for the metallurgical industry, for which the conceptual framework was used as a basis. Within this framework, the technology innovation stages of product development and implementation are still shown, albeit in slightly lighter shading; this was done intentionally to prevent a reader from thinking (wrongly) that these two important stages do not form part of the technology innovation process. The stages of product development and implementation were excluded from a detailed evaluation for this study; however, it would be of considerable value if an in-depth case study evaluation was also performed for these stages, as part of a future study.

The framework, shown in Figure 9, illustrates the cyclical technology innovation process, which focuses specifically on the initial stages of concept development and R\&D. The most important factors that impact technology commercialization during the early stages of the innovation process are shown, while the top-ranking factors are highlighted in bold, italic. The central driver of the entire technology innovation process is the market.

It is suggested that this framework could assist technology managers within the metallurgical industry to perform the initial stages of technology innovation, with the aim of technology commercialization, with greater focus and structure, and increase the likelihood of technology commercialization. By focusing attention and resources on the indicated factors that are relevant to each technology development stage, the technology innovation process should progress at a faster rate, and with potentially greater success, compared with a scenario in which this framework is not applied. The application of this framework has relevance to the innovation process of any technology that is typically developed according to similar stages to those within the metallurgical industry, as indicated in the framework.

Furthermore, a contribution is made to theory in the form of the internal and external loops that are shown in the framework; these indicate interactions that are both internal and external to the technology innovation process. In particular, open innovation and the formation of networks were not found in existing frameworks; and so their inclusion contributes a new dimension to current frameworks for technology commercialization.

\section{Conclusions}

This study aimed to identify the driver of technology commercialization, along with an evaluation of internal and external factors influencing the technology innovation stages of concept development and $R \& D$, and to consolidate these aspects into a framework for a successful technology commercialization front-end for the metallurgical industry.

Insights from a literature review were applied to construct a conceptual framework that illustrates the technology innovation process, with four integrated stages of concept development, $R \& D$, product development, and implementation. For this study, only the first two stages of the technology innovation process were evaluated. The conceptual framework was used as the basis for the collection of data for each case. Appropriate secondary data was reviewed, followed by two interviews per case. The findings from both cases were evaluated, compared, and consolidated into a single list of factors that contribute to successful technology commercialization in the metallurgical industry, with a focus on the initial stages of the technology innovation process.

During concept development, the most important factors that impact technology commercialization were found to be an appropriate identification of the need or opportunity within the market, along with an accurate formulation of the vision and purpose of the technology. The identification of the need within the market was the top-ranked factor for the stage of concept development. Further key factors were identified to be the development of a conceptual business case for the technology,

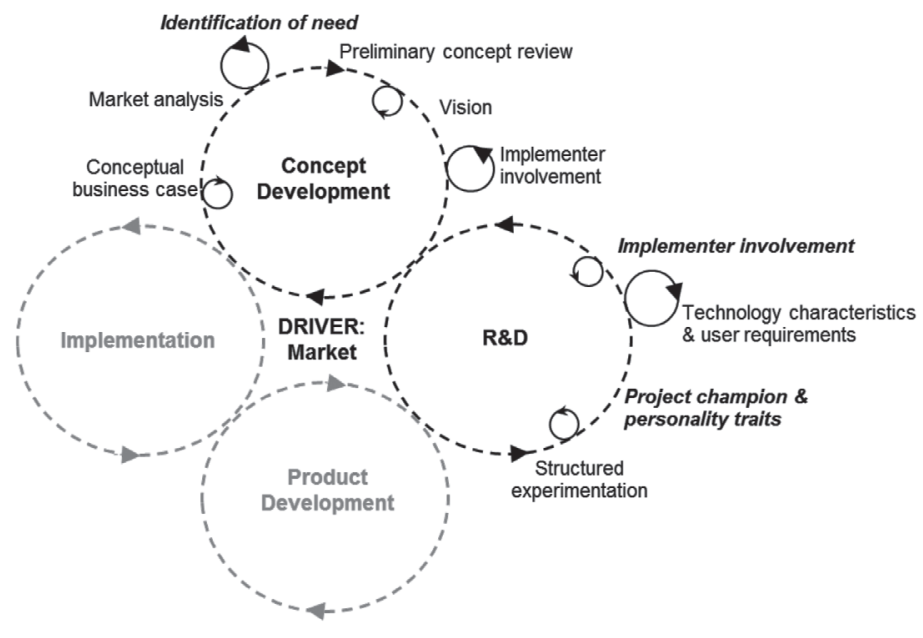

Figure 9-Technology commercialization front-end framework for the metallurgical industry 


\section{Technology commercialization front-end framework: Metallurgical industry}

and a thorough market analysis, along with preliminary concept reviews of the technology. The involvement of an implementer was also found to be preferred during concept development; however, it might not be possible to identify and involve a potential implementer during such early stages of technological development.

During $R \& D$, the involvement of a potential implementer becomes considerably more important for the description of the technical specification and user requirements, along with a project champion who will drive the technology development programme in a structured manner, while focused, minimal experimentation is done by a competent team. The top-ranked factors for the stage of $R \& D$ were found to be the involvement of an implementer and the presence of a project champion and a suitable team.

The central driver of technology commercialization was identified as the existence of a susceptible market, along with the fulfilment of a need or opportunity within the market. It is critically important that appropriate analysis is done to identify the market and its needs or opportunities accurately.

The driver of technology commercialization, along with the factors that influence the commercialization of technologies during the stages of concept development and $R \& D$, was translated into a framework that highlights important aspects related to the development of technologies in the metallurgical industry. Researchers and technology managers would be able to apply this framework during the development of almost any technology in the metallurgical industry, irrespective of its uniqueness. The framework is therefore presented as a practical guideline for technology managers and researchers who are involved in technology development with the ultimate objective of technology commercialization in the metallurgical industry.

\section{Recommendations}

For this research study, only the stages of concept development and $R \& D$ were evaluated; thus it is recommended that case studies be performed in which the stages of product development and implementation are also evaluated, to enable a holistic view of the entire technology innovation process.

Furthermore, it is recommended that the validity of the framework be evaluated in several ways. First, this could be done by expanding the study to include more cases of technologies that were successfully commercialized in the metallurgical industry. Second, it would be of value if more informants were available to be interviewed and thereby increase the sample distribution. Third, it is recommended that this framework be validated by applying it during the development of an actual technology related to the metallurgical industry. Finally, the validity of the framework might be tested during the development of a technology external to the metallurgical industry.

For future research, it would be of value if the interrelationships between the various factors could be determined and quantified. This might be done by an in-depth evaluation of the extent of influence and impact between the various factors, and highlighting the most important relationships in a quantitative manner.

\section{Contributions}

Michelle van Rooyen conducted the study and wrote the article. Elma van der Lingen supervised the study. Victor Ross provided guidance on the framework.

\section{References}

AarikKa-Stenroos, L., Sandberg, B., and LehtimÄKI, T. 2014. Networks for the commercialization of innovations: A review of how divergent network actors contribute. Industrial Marketing Management, vol. 43, no. 3. pp. 365-381.

Alekseevna, M.A. 2014. Evolution of the innovation process models. International Journal of Econometrics and Financial Management, vol. 2, no. 4. pp. 119-123.

BAKALARCZYK, S. 2013. Managing innovation in metallurgy. Proceedings of Metal 2013: The 22nd International Conference on Metallurgy and Materials,. Brno, Czech Republic. Tanger, Ostrave.

BARR, S.H., BAKER, T., MARKHAM, S.K., and Kingon, A.I. 2009. Bridging the valley of death: Lessons learned from 14 years of commercialization of technology education. Academy of Management Learning and Education, vol. 8, no. 3. pp. 370-388.

Berkhout, A., Hartmann, D., van der Duin, P., and Ortt, R. 2006. Innovating the innovation process. International Journal of Technology Management, vol. 34 no. (3-4. pp. 390-404

Berkhout, G., Hartmann, D. and Trott, P. 2010. Connecting technological capabilities with market needs using a cyclic innovation model. RandD Management, vol. 40, no. 5. pp. 474-490.

BLANk, S. 2013. Why the lean start-up changes everything. Harvard BusinesS Review, vol. 91, no. 5. pp. 63-72.

Cetindamar, D., Phanl, R., and Probert, D. 2009. Understanding technology management as a dynamic capability: A framework for technology management activities. Technovation, vol. 29, no. 4. pp. 237-246.

Cetindamar, D., PhaAl, R., and Probert, D. 2010. Technology Management Activities and Tools. Palgrave MacMillan, Basingstoke, New York:

Cooper, R.G. 1990. Stage-gate systems: a new tool for managing new products. Business Horizons, vol. 33, no. 3. pp. 44-54.

Cooper, R.G. 2014. What's next?: After stage-gate. Research-Technology Management, vol. 57, no. 1. pp. 20-31.

Ford, N., Trotr, P., Simms, C. and Hartmann, D. 2014. Case analysis of innovation in the packaging industry using the cyclic innovation model. International Journal of Innovation Management, vol. 18, no. 5. pp. 1450033.

Geissdoerfer, M., Savaget, P. and Evans, S. 2017. The Cambridge business model innovation process. Procedia Manufacturing, vol. 8. pp. 262-269

Ismail, N., Nor, M.J.M., and SIDEK, S. 2015. A framework for a successful research products commercialisation: A case of Malaysian academic researchers. Procedia Social and Behavioral Sciences, vol. 195. pp. 283-292.

Kirchberger, M.A. and PoHL, L. 2016. Technology commercialization: A literature review of success factors and antecedents across different contexts. Journal of Technology Transfer, vol. 41, no. 5. pp. 1077-1112.

LichtenTHALER, U. 2006. External technology commercialisation as an alternative mode of technology marketing. International Journal of Technology Marketing, vol. 1, no. 4. pp. 411-430.

LichtentHALER, U. 2008a. External technology commercialisation projects: objectives, processes and a typology. Technology Analysis and Strategic Management, vol. 20, no. 4. pp. 483-501.

LichTENTHALER, U. 2008b. Open innovation in practice: An analysis of strategic approaches to technology transactions. IEEE Transactions on Engineering Management, vol. 55, no. 1. pp. 148-157.

Markman, G.D., SiEgel, D. S., and WRIGHT, M. 2008. Research and technology commercialization. Journal of Management Studies, vol. 45, no. 8. pp. 1401-1423.

OstendoRf, J., MouzAs, S., and CHAKRABARTI, R. 2014. Innovation in business networks: The role of leveraging resources. Industrial Marketing Management, vol. 43, no. 3. pp. 504-511.

Polampally, D. 2013. 3M case study. https://www.slideshare.net/ dheerajrockzzzzzzz/3-m-28515597 [accessed 16 August 2017].

Ross, V.E. and KLEIngeld, A.W. 2006. Mapping and measuring: A holistic approach to auditing innovation. Measuring Innovation in $O E C D$ and non-OECD Countries Blankley, W., Scerri, M., Molotja, N., and Saloojee, I. (eds). HSRC Press, Cape Town, South Africa: Ch. 5 , p. 73.

Sauser, B., Verma, D., Ramirez-Marouez, J., and Gove, R. 2006. From TRL to SRL: The concept of systems readiness levels. Proceedings of the Conference on Systems Engineering Research, Los Angeles, CA. http://citeseerx.ist.psu.edu/viewdoc/ download?doi=10.1.1.562.3338\&rep=rep1\&type=pdf

Schumpeter, J. A. 1939. Business Cycles. McGraw-Hill, New York:

SHERMAN, J. 2015. PMP/CAPM prep workshop intro and scope. https://slideplayer. com/slide/5274084/ [accessed 10 August 2018].

TAYlor, M. and TAylor, A. 2012. The technology life cycle: Conceptualization and managerial implications. International Journal of Production Economics, vol 140 , no. 1. pp. 541-553.

TidD, J. 2006. A review of innovation models. Imperial College, London. https://pdfs. semanticscholar.org/73bf/8d2e702b47b45666d47522ce28d8595e103a.pdf

Ungureanu, M., Pop, N., and Ungureanu, N. 2016. Innovation and technology transfer for business development. Procedia Engineering, vol. 149. pp. 495-500.

VAN DER DUIN, P., ORTT, R., and Кок, M. 2007. The cyclic innovation model: A new challenge for a regional approach to innovation systems? European Planning Studies, vol. 15, no. 2. pp. 195-215.

Van der Heiden, P., Pohl, C., Mansor, S., and van Genderen, J. 2016. Necessitated absorptive capacity and metaroutines in international technology transfer: A new model. Journal of Engineering and Technology Management, vol. 41. pp. 65-78.

VAN Rooyen, M. 2018. A framework for a successful technology commercialisation front-end for the metallurgical industry. M. Eng. Mgmt. -dissertation, University of Pretoria. 